\title{
Synthesis and Characterization of New Cardo Polyimides Containing Pendent Norbornane Group
}

\author{
Der-Jang LiAW ${ }^{\dagger}$ and Been-Yang LiAw \\ Department of Chemical Engineering, \\ National Taiwan University of Science and Technology, \\ Taipei, Taiwan 106, Republic of China
}

(Received May 26, 1999)

\begin{abstract}
KEY WORDS 2,2-Bis[4-(4-aminophenoxy)phenyl]norbornane / Polyimide / Cardo Group / Solubility / Thermal Property / Tensile Property / Crystallinity /
\end{abstract}

\begin{abstract}
Outstanding properties of aromatic polyimides such as excellent thermo-oxidative stability and superior chemical resistance has led to the use of polyimides as insulating materials for electronics, semipermeable membranes for gas separation and high-temperature adhesives and coatings. ${ }^{1}$ In general, aromatic polyimides are insoluble and intractable or only processable under extreme conditions. A great deal of research on the polyimides has been made on increasing processability with minimal effect on thermal stability as well as improvement of their specific properties, such as the introduction of bulky substituent ${ }^{2-6}$ or pendent groups ${ }^{7-10}$ along the polymer backbone to improving processability of the polyimides while maintaining thermal stability.
\end{abstract}

The introduction of cardo (Latin meaning loop) groups into the backbone of polymers is another approach for improving solubility and thereby processability. Cardo polymers exhibit valuable properties: increased thermal stability with increased solubility in organic solvents because the specific contribution of the cardo group. ${ }^{11-14}$ Previously we found several means for the introduction of cardo groups such as alicyclic cyclododecylidene, ${ }^{15}$ polyalicyclic adamantane ${ }^{16}$ and tricyclo $\left[5.2 .1 .0^{2,6}\right]$ decane $^{17}$ groups in the polymer backbone. The solubility of polyimide was enhanced while high glass transition temperature and thermal stability were maintained. ${ }^{15-17}$

A new family of cardo polyimides derived from a norbornane-containing diamine, 2,2-bis[4-(4-aminophenoxy) phenyl]norbornane (BAPN), was synthesized. The synthesis and characterization of the new polyimides are discussed.

\section{EXPERIMENTAL}

\section{Synthesis of Monomer}

2,2-Bis[4-(4-nitrophenoxy)phenyl]norbornane (BNPN). A mixture of 2,2-bis(4-hydroxyphenyl)norbornane (BHPN) $(3.0 \mathrm{~g}, 10.7 \mathrm{mmol}), p$-chloronitrobenzene $(3.4 \mathrm{~g}$, $21.4 \mathrm{mmol})$, potassium carbonate $(3.37 \mathrm{~g})$ and $N, N$-dimethylformamide (DMF, $16 \mathrm{~mL}$ ) was refluxed for $8 \mathrm{~h}$. The mixture was cooled and poured into methanol-water
(1:1 by volume). The crude product, 2,2-bis[4-(4nitrophenoxy)phenyl]norbornane (BNPN), was recrystallized from DMF to provide yellow needles (mp $153-155^{\circ} \mathrm{C}$ ) in $83 \%$ yield. IR (KBr): 1577 and $1336 \mathrm{~cm}^{-1}$ $\left(\mathrm{NO}_{2}\right)$, and $1240 \mathrm{~cm}^{-1}(\mathrm{C}-\mathrm{O}-\mathrm{C}) ;{ }^{1} \mathrm{H}$ NMR (dimethyl sulfoxide (DMSO)- $\left.d_{6}, \mathrm{ppm}\right): \delta=8.23-8.19(\mathrm{~m}, 4 \mathrm{H}$, $7.48-7.42(\mathrm{dd}, 4 \mathrm{H}) ; 7.08-7.02(\mathrm{~m}, 8 \mathrm{H}) ; 3.34-1.13(\mathrm{~m}$, $10 \mathrm{H})$. Anal. Calcd for $\mathrm{C}_{31} \mathrm{H}_{26} \mathrm{O}_{6} \mathrm{~N}_{2}: \mathrm{C}, 71.25 \% ; \mathrm{H}$, $5.01 \%$; N, 5.36\%; found: C, $70.95 \% ; \mathrm{H}, 4.97 \%$; , $5.10 \%$.

2,2-Bis[4-(4-aminophenoxy)phenyl]norbornane (BAPN). Hydrazine monohydrate $(10 \mathrm{~mL})$ was added dropwise to a mixture of BNPN $(4.0 \mathrm{~g}, 7.6 \mathrm{mmol})$, ethanol $(20 \mathrm{~mL})$, and a catalytic amount of $10 \%$ palladium on activated carbon $(\mathrm{Pd} / \mathrm{C}, 0.05 \mathrm{~g})$ at the boiling temperature. The reaction mixture was refluxed for $24 \mathrm{~h}$ and filtered to remove $\mathrm{Pd} / \mathrm{C}$. After cooling, the precipitated crystals, 2,2-bis[4-(4-aminophenoxy)phenyl]norbornane (BAPN), were isolated by filtration and recrystallized from ethanol. The yield was $79 \%$; mp $149-150^{\circ} \mathrm{C}$.

Anal. Calcd for $\mathrm{C}_{31} \mathrm{H}_{30} \mathrm{O}_{2} \mathrm{~N}_{2}:$ C, $80.49 \% ; \mathrm{H}, 6.54 \%$; N, $6.06 \%$; found: C, $80.32 \%$; H, $6.40 \%$; N, $6.32 \%$.

\section{Preparation of Polymers}

Aromatic dianhydride $(1.3 \mathrm{mmol})$ was added in one portion to a solution of diamine BAPN $(0.601 \mathrm{~g}$, $1.3 \mathrm{mmol}$ ) in $7 \mathrm{~mL} N, N$-dimethylacetamide (DMAc) at room temperature under argon atmosphere. The solution was stirred for another $3 \mathrm{~h}$ to obtain viscous polyamic acid solution. The viscous polyamic acid solution was cast on a glass plate and preheated at $80^{\circ} \mathrm{C}$ for $12 \mathrm{~h}$ to remove DMAc. The polyamic acid film was heated from 100 to $300^{\circ} \mathrm{C}$ for $3 \mathrm{~h}$, and the temperature was held at $300^{\circ} \mathrm{C}$ for $1 \mathrm{~h}$ under vacuum. The polyamic acid film was converted to brown, tough and flexible polyimide film. Chemical cyclodehydration was carried out by adding extra DMAc, $0.5 \mathrm{~mL}$ of acetic anhydride and $0.4 \mathrm{~mL}$ pyridine to the above polyamic acid solution with stirring at room temperature for $1 \mathrm{~h}$ and heating at $100^{\circ} \mathrm{C}$ for $3 \mathrm{~h}$, and subsequently poured into methanol to afford polyimide powder.

\footnotetext{
${ }^{\dagger}$ To whom correspondence should be addressed (Phone: 886-2-27376638 or 886-2-27335050, Fax: 886-2-23781441 or 886-2-27376644, e-mail: liaw@ch.ntust.edu.tw). 


\section{RESULTS AND DISCUSSION}

Scheme 1 illustrates the synthetic procedure of the new diamine monomer BAPN. The bisphenol compound

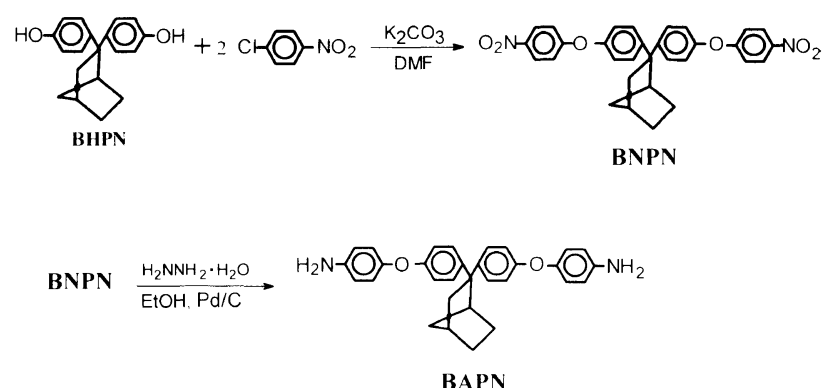

Scheme 1. Synthesis of 2,2-bis[4-(4-aminophenoxy)phenyl]norbornane (BAPN).
BHPN was synthesized from reaction of norcamphor with excess phenol using hydrogen chloride as catalyst as well as 3 -mercaptopropionic acid as cocatalyst. The dinitro compound BNPN was obtained through aromatic nucleophilic substitution of BHPN with $p$-chloronitrobenzene in the presence of potassium carbonate. The catalytic hydrogenation of compound BNPN to diamine BAPN was accomplished using hydrazine monohydrate as well as a catalytic amount of $\mathrm{Pd} / \mathrm{C}$. The chemical structures of compounds BNPN and BAPN were established by elemental analysis, IR spectroscopy and NMR analysis. Figures 1(A) and 1(B) show the ${ }^{13} \mathrm{C}$ and ${ }^{1} \mathrm{H}$ NMR spectra of the new diamine BAPN, respectively.

Cardo polyimides were prepared from diamine BAPN and commercially available aromatic dianhydrides (DAa-DAe) through ring-opening polyaddition and

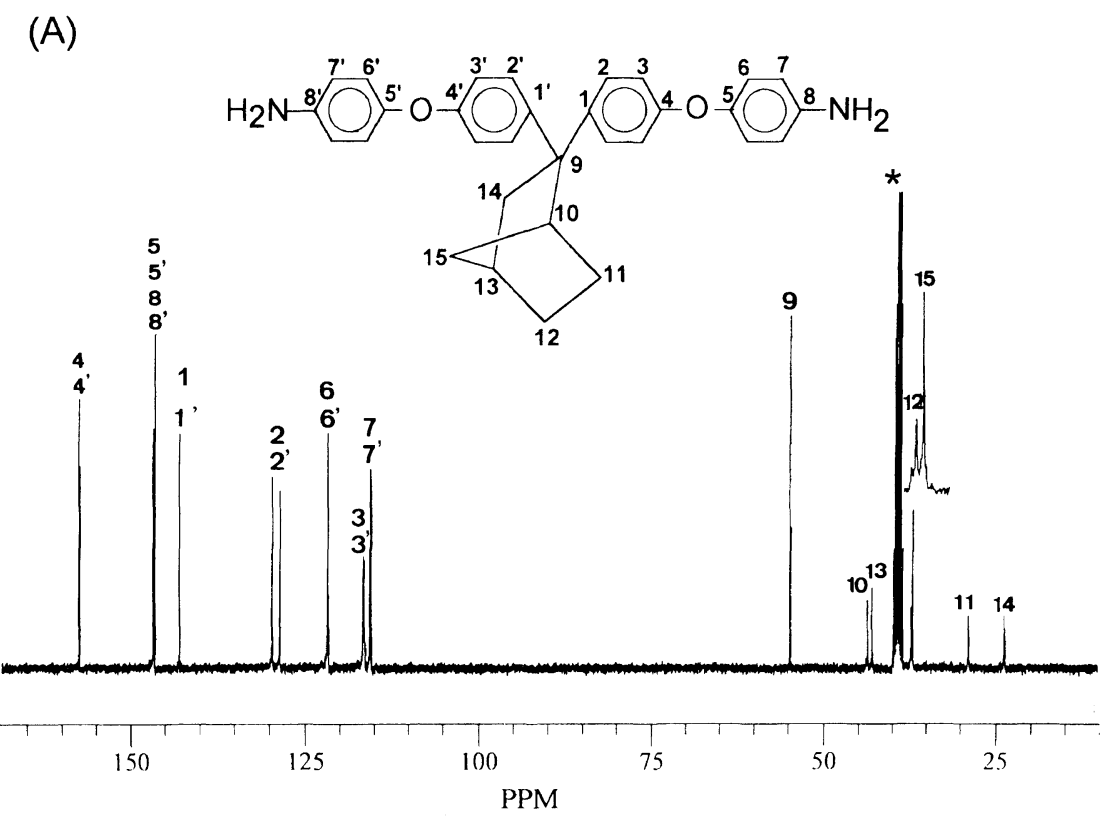

(B)

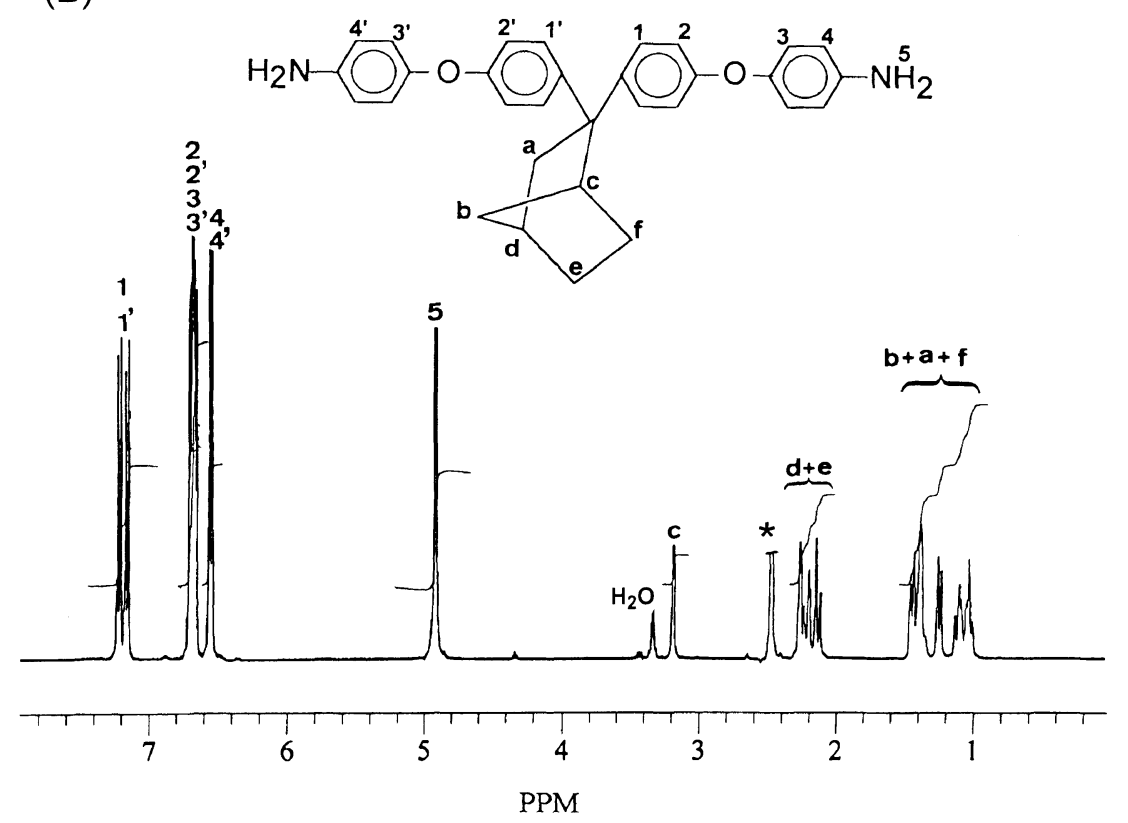

Figure 1. NMR spectra of BAPN in DMSO- $d_{6}$ : (A) ${ }^{13} \mathrm{C}$ NMR and (B) ${ }^{1} \mathrm{H}$ NMR (*: solvent peak). 
subsequent cyclodehydration as shown in Scheme 2. The ring-opening polyaddition in DMAc at room temperature afforded viscous polyamic acid solutions. The

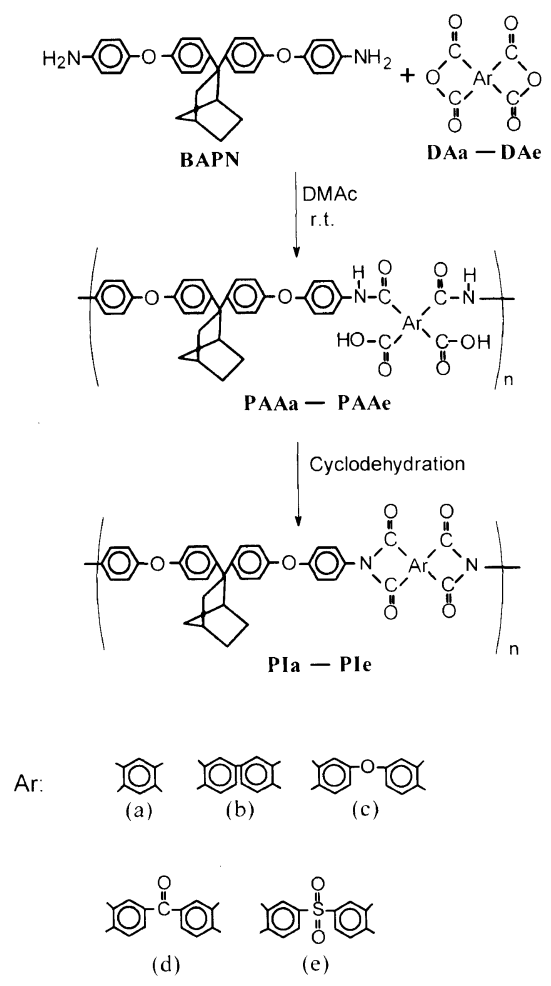

Scheme 2. Preparation of cardo polyimides. inherent viscosity of polyamic acid was $1.02-1.82 \mathrm{dL}$ $\mathrm{g}^{-1}$ (Table I). The polyamic acids were cast on a glass plate and preheated to give the polyamic acid films. Thermal conversion to polyimides was carried out by successive heating of the films to $300^{\circ} \mathrm{C}$ under vacuum. Brownish, transparent and fingernail creasable films were obtained. Chemical cyclodehydration of polyamic acids with a dehydrating agent such as a mixture of acetic anhydride and pyridine was effective in obtaining polyimides. The resulting polyimides which dissolved in $N$-methyl-2-pyrrolidine (NMP) had inherent viscosity of $0.70-0.85 \mathrm{dL} \mathrm{g}^{-1}$. The solution cyclodehydration method using xylene as an azeotroping reagent was also carried out in the case of polymerization of PIa. PIa precipitation occurred during solution cyclodehydration while gelation, during chemical imidization.

The crystallinity of these new cardo polyimides was estimated by wide-angle X-ray diffractograms. All cardo polyimides exhibited amorphous patterns. The amorphous behavior of the cardo polyimides is due to bulky planar substituents, which disrupt the symmetry of macromolecules and prevent ordering. A cardo group also decreased the intermolecular force between the polymer chains, causing decrease in crystallinity.

The solubility behavior of the polyimides obtained by chemical cyclodehydration is listed in Table I. Polymers PIc and PIe derived from ether- and sulfonyl-contained dianhydride, respectively, showed good solubility in NMP, DMAc, $N, N$-dimethylformamide, pyridine, cyclohexanone, and tetrahydrofuran at room temperature or

Table I. Synthesis and solubility of polyimides

\begin{tabular}{|c|c|c|c|c|c|c|c|c|c|c|c|}
\hline \multicolumn{2}{|c|}{ Polyamic acid } & \multicolumn{10}{|c|}{ Polyimide $^{b}$} \\
\hline \multirow{2}{*}{ Code } & \multirow{2}{*}{$\frac{\eta_{\text {inh }}^{\text {a }}}{\mathrm{dL} \mathrm{g}^{-1}}$} & \multirow{2}{*}{ Code } & \multirow{2}{*}{$\frac{\eta_{\mathrm{inh}}{ }^{\mathrm{c}}}{\mathrm{dL} \mathrm{g}^{-1}}$} & \multirow{2}{*}{ Remark $^{\mathrm{e}}$} & \multicolumn{7}{|c|}{ Solubility ${ }^{f}$} \\
\hline & & & & & NMP & DMAc & DMF & DMSO & Py & $\begin{array}{l}\text { Cyclo- } \\
\text { hexanone }\end{array}$ & THF \\
\hline PAAa & 1.82 & PIa & $-^{\mathbf{d}}$ & G & - & - & - & - & - & - & - \\
\hline PAAb & 1.02 & $\mathrm{PIb}$ & 0.70 & $\mathbf{P}$ & ++ & - & - & - & ++ & - & - \\
\hline PAAc & 1.51 & PIc & 0.85 & $\mathrm{~S}$ & ++ & ++ & ++ & + & ++ & + & ++ \\
\hline PAAd & 1.42 & PId & $-^{\mathrm{d}}$ & $\mathrm{P}$ & - & - & - & - & - & - & - \\
\hline PAAe & 1.54 & $\mathrm{PIe}$ & 0.80 & $\mathrm{~S}$ & ++ & ++ & ++ & ++ & ++ & ++ & ++ \\
\hline
\end{tabular}

${ }^{a}$ Measured in DMAc at $0.5 \mathrm{~g} \mathrm{dL}^{-1}$ at $30^{\circ} \mathrm{C}$. ${ }^{\mathrm{b}}$ Obtained by chemical imidization from the corresponding polyamic acids. ${ }^{\mathrm{c}}$ Measured in NMP at $0.5 \mathrm{~g} \mathrm{dL}^{-1}$ at $30^{\circ} \mathrm{C}$. ${ }^{\mathrm{d}}$ Could not dissolved in NMP. ${ }^{\mathrm{e}}$ Features of the polymerization mixture: G, gelation; P, polymer precipitation; S, homogeneous solution. ${ }^{\mathrm{f}}$ Solubiltiy: ++ , soluble at room temperature; + , soluble on heating; +- , partial soluble on heating; - , insoluble; Abbreviations: NMP, $N$-methyl-2-pyrrolidine; DMAc, $N, N$-dimethylacetamide; DMF, $N, N$-dimethylformamide; DMSO, dimethylsulfoxide; Py, pyridine; THF, tetrahydrofuran.

Table II. Thermal and tensile properties of polyimides

\begin{tabular}{|c|c|c|c|c|c|c|}
\hline \multirow{3}{*}{$\begin{array}{l}\text { Polymer } \\
\text { code }\end{array}$} & \multirow{3}{*}{$\frac{\mathrm{DSC}}{T_{\mathrm{g}}^{\mathrm{a}}}$} & \multirow{2}{*}{\multicolumn{2}{|c|}{$\frac{\text { TGA }}{T_{\mathrm{d}_{10}}{ }^{\mathrm{c}} /{ }^{\circ} \mathrm{C}}$}} & \multirow{3}{*}{$\begin{array}{c}\begin{array}{c}\text { Tensile } \\
\text { strength }\end{array} \\
\mathrm{MPa}\end{array}$} & \multirow{3}{*}{$\begin{array}{c}\begin{array}{c}\text { Elongation } \\
\text { at break }\end{array} \\
\%\end{array}$} & \multirow{3}{*}{$\begin{array}{c}\begin{array}{c}\text { Tensile } \\
\text { modulus }\end{array} \\
\text { GPa }\end{array}$} \\
\hline & & & & & & \\
\hline & & In $\mathrm{N}_{2}$ & In air & & & \\
\hline PIa & $-^{\mathrm{b}}$ & 513 & 532 & 145 & 9 & 2.7 \\
\hline PIb & 283 & 526 & 547 & 128 & 19 & 2.3 \\
\hline PIc & 261 & 522 & 549 & 141 & 8 & 2.6 \\
\hline PId & 269 & 526 & 551 & 156 & 7 & 2.8 \\
\hline PIe & 288 & 500 & 511 & 144 & 6 & 2.3 \\
\hline
\end{tabular}

${ }^{\mathrm{a}}$ Glass transition temperature $\left(T_{\mathrm{g}}\right)$ measured on DSC at heating rate of $20^{\circ} \mathrm{Cmin}^{-1}$. ${ }^{\mathrm{b}}$ Not detectable by DSC. ${ }^{\mathrm{c}}$ Temperature at which $10 \%$ weight loss was recorded on TGA at heating rate of $20^{\circ} \mathrm{Cmin}^{-1}$. 
upon heating at $70^{\circ} \mathrm{C}$. Other polyimides derived from rigid and symmetric dianhydrides exhibited limited solubility. The polymer derived from dianhydride DAb dissolved in NMP and pyridine. The good solubility of these polyimides was due to the presence of the bulky pendent group, which did not allow for dense chain packing and decreased crystallinity.

The thermal behavior of the norbornane-containing cardo polyimides is summarized in Table II. These polyimides, except PIa, displayed distinct glass transition with the second heating of DSC traces, whereas endotherms or exotherms were completely lacking. These polyimides had glass transition temperatures $\left(T_{\mathrm{g}} \mathrm{s}\right)$ of $261-288^{\circ} \mathrm{C}$, depending on dianhydride component structure. Thermogravimetric analysis (TGA) traces revealed that all the polyimides not to decompose around or below $500^{\circ} \mathrm{C}$ in nitrogen and air. Decomposition temperatures of $10 \%$ weight loss $\left(T_{\mathrm{d}_{10}}\right)$ were $500-526$ and $511-551^{\circ} \mathrm{C}$ in nitrogen and air, respectively.

The tensile properties of the tough polyimide films obtained by thermal cyclodehydration are summarized in Table II. Tensile strength was $128-156 \mathrm{MPa}$, elongation at break, $6-19 \%$ and tensile modulus, $2.3-2.8$ $\mathrm{GPa}$. This demonstrates that these polyimide films are strong materials.

Acknowledgment. The authors thank the National Science Council of the Republic of China for support of this work under grant NSC 89-2216-E011-008.

\section{REFERENCES}

1. J. M. Sonnett and T. P. Gannett, "Polyimides: Fundaments and Applications," M. K. Ghosh and K. L. Mittal, Ed., Marcel Dekker, New York, N.Y., 1996.

2. H. J. Jeong, Y. Oishi, M. Kakimoto, and Y. Imai, J. Polym. Sci. Part A, Polym. Chem., 29, 39 (1991).

3. D. J. Liaw and B. Y. Liaw, Polym. J., 28, 970 (1996).

4. D. J. Liaw, B. Y. Liaw, L. J. Li, B. Sillion, R. Mercier, R. Thiria and H. Sekiguchi, Chem. Mater., 10, 734 (1998).

5. X. Sun, Y. K. Yang, and F. Lu, Macromolecules, 31, 4291 (1998).

6. I. K. Spiliopoulos and J. A. Mikroyannidis, Macromolecules, 31, 515 (1998).

7. K. H. Park, T. Tani, M. A. Kakimoto, and Y. Imai, J. Polym. Sci., Part A, Polym. Chem., 36, 1767 (1998).

8. Y. Kasashima, H. Kumada, K. Yamamoto, F. Akutsu, K. Naruchi, and M. Miura, Polymer, 36, 645 (1995).

9. M. H. Yi, W. Huang, M. Y. Jin, and K. Y. Choi, Macromolecules, 30, 5606 (1997).

10. D. Ayala, A. E. Lozano, J. G. de la Campa, and J. de Abajo, Polym. Prepr., Am. Chem. Soc., Div. Polym. Chem., 39, 359 (1998).

11. V. V. Korshak, S. V. Vinogradova, and Y. S. Vygodski, J. Macromol. Sci., Rev. Macromol. Chem., C11, 45 (1974).

12. N. Biolley, M. Gregoire, T. Pascal, and B. Sillion, Polymer, 32, $3256(1991)$

13. M. D. Joshi, A. Sarkar, O. S. Yemul, P. P. Wadgaonkar, S. V. Lonikar, and N. N. Maldar, J. Appl. Polym. Sci., 64, 1329 (1997).

14. J. K. Stille, R. M. Harris, and S. M. Padaki, Macromolecules, 14, 486 (1981).

15. D. J. Liaw and B. Y. Liaw, Polymer, 40, 3183 (1999).

16. D. J. Liaw and B. Y. Liaw, Macromol. Chem. Phys., 200, 1326 (1999).

17. D. J. Liaw, B. Y. Liaw, and C. Y. Chung, J. Polym. Sci., Part A, Polym. Chem., 37, 2815 (1999). 